\title{
INCIDENCE OF ECHINOCOCCOSIS IN THE PLEVEN REGION OF BULGARIA IN THE PERIOD 1998-2017
}

\author{
Martin P. LALEV ${ }^{1}$, Joana I. SIMEONOVA ${ }^{2}$, Ludmil S. STOYANOV ${ }^{\bowtie}$, Zheni S. BOSHNAKOVA ${ }^{3}$, \\ Ivelin A. ANGELOV ${ }^{4}$ \\ ${ }^{1}$ Laboratory of Parasitology, University Hospital - Pleven, Bulgaria \\ ${ }^{2}$ Department of Pharmaceutical Sciences and Social Pharmacy, Faculty of Pharmacy, Medical University - \\ Pleven, Bulgaria \\ ${ }^{3}$ Department of Infectious Diseases Control, Regional Health Inspectorate - Pleven, Bulgaria \\ ${ }^{4}$ Department of Infectious Diseases, Epidemiology, Parasitology and Tropical Medicine, Medical \\ University - Pleven, Bulgaria
}

Received 03 Jan 2020, Corrections received 19 Jan 2020, Accepted 11 Febr 2020

https://doi.org/10.31688/ABMU.2020.55.1.11

\section{Abstract}

Introduction. Cystic echinococcosis (CE) is a zoonotic parasitosis still encountered in Balkan countries. Bulgaria is a country with a high incidence of CE and ranks first among the countries of European Union.

Objectives. The study aimed at analyzing the trends in CE incidence from 1998 to 2017 in the Pleven region of Bulgaria and of finding out if the implementation of the Bulgarian national program for control of cystic echinococcosis in humans and animals has resulted in the decrease of the disease rates.

Methods. This study of echinococcosis in the Pleven region covers 20 years (1998-2017) and is divided into two parts: before and after the introduction of the 5-year program for control. Data were collected from epidemiological records and histories of 248 subjects with primary CE.

Results. A high incidence was registered during the first studied period $(1998-2007)-5.27 \%$, which in 1999 reached $8.14 \%$ ooo. After implementation of the national program, the yearly incidence of hydatid disease showed a statistically significant decrease,

\section{RÉSUMÉ}

Étude de l'incidence de l'échinococcose dans la région de Pleven pour la période 1998-2017

Introduction. L'échinococcose kystique (EC) est une parasitose zoonotique de grande importance médicale et sociale pour l'homme. La Bulgarie est un pays avec une incidence élevée d'EC et est classée au premier rang des pays de l'Union européenne par le nombre de cas enregistrés chaque année.

Objectifs. L'objectif de l'étude est d'analyser l'incidence de l'échinococcose dans la région de Pleven au cours de la période 1998-2017 et d'évaluer si la mise en ouvre du programme national du contrôle de EC chez l'homme et l'animal a entraîné une diminution du taux d'incidence.

Méthodes. L'étude couvre une période de 20 ans (1998-2017), divisée en deux parties : avant et après l'introduction d'un programme de 5 ans pour le contrôle de l'échinococcose chez l'homme. Les données des dossiers médicaux de 248 personnes atteintes de TDM primaire ont été utilisées. 
reaching $2.42 \%$ in 2017. The analysis of the data showed that the incidence was higher among working-age people and in the 5-19 years old age group.

Conclusions. The persistence of a relatively high incidence in the young age group is a sign of continuing active transmission of the infection and demonstrates the necessity to continue active measures.

Keywords: cystic echinococcosis, Echinococcus granulosus, incidence.

Abbreviations: $\mathrm{CE}=$ Cystic Echinococcosis; PAIR $=$ puncture-aspiration-injection-reaspiration.

\section{INTRODUCTION}

Cystic echinococcosis (CE) is a zoonotic parasitosis still encountered in Balkan countries. The etiological agent is Echinococcus granulosus, a small tapeworm that dwells in the intestinal tract of dogs, jackals, wolves, and other carnivorous animals. The larval form of the parasite, hydatid cyst, is the form of the parasite that is found in humans ${ }^{1}$.

Human CE is a severe, chronic disease, with relapses that may lead to complications and death. Bulgaria is a country with a high incidence of CE and ranks first among the European Union (EU) countries in number of cases registered per year ${ }^{2}, 3$.

Over the last decades, there has been a negative trend related to CE. More and more often, the disease is diagnosed in young patients, and this accounts for almost one-fourth of all patients operated for $\mathrm{CE}^{4,5}$. The number of cases of primary multi-organ and complicated CE has also increased ${ }^{6}$. The high disease rate of CE, that in 2001 was as high as $9.21 \%$ necessitated the implementation in 2004 of a nationwide program for the control of CE in animals and humans ${ }^{7}$. Despite the drop in incidence after the program started $(3.95 \%$ in 2010$)$, over the following years, the incidence increased again and has stayed high ${ }^{6}$.

The objective of the STUDY was to analyze the trends in CE incidence from 1998 to 2017 in the Pleven region, and find out if the implementation of the national program for control of the disease has resulted in the decrease of the disease rates.
Résultats. Au cours de la première période de l'étude (1998-2007), une incidence moyenne élevée d'échinococcose a été enregistrée - 5,27\% \% qui en 1999 a atteint $8,14 \%$. Après l'introduction du programme national, l'incidence annuelle moyenne de l'EC a montré une tendance à la baisse statistiquement significative et a atteint 2,42\% en 2017. L'analyse des données montre que l'incidence est plus élevée dans le groupe d'âge de 5 à 19 ans et chez les personnes en âge de travailler.

Conclusions. Le maintien d'une incidence relativement élevée dans le groupe d'âge jeune est un signe de transmission réelle continue de l'invasion et indique la nécessité d'interventions actives continues à la source.

Mots-clés: échinococcose kystique, Echinococcus granulosus, incidence.

\section{Materials AND MEthods}

The study on the incidence of CE in the Pleven region covers twenty years (1998-2017). We used data from medical records of 248 subjects with primary CE. All patients were diagnosed intraoperatively, and the diagnoses were confirmed by histological and cytological tests in those who underwent PAIR therapy.

We collected data regarding age, sex, place of residence, and the year of surgery. The category variables were described as a number and percentage of patients in each category of a variable. Age is a quantitative variable that was described by the median $(\mathrm{Mdn})$ and the range (minimal and maximal value of the variable in the order statistics).

For statistical analysis, we divided the patients into age groups. When defining the level of age-adjusted incidence rates, the following groups were formed: 0-14 years, $15-59$ years, and 60+years (the Bulgarian population). Then, the second and the third age groups were changed to 15-64 years and 65+ years (standard European population). Data of the Pleven region population were used by the Regional Health Inspectorate - Pleven ${ }^{8}$. Also, we used data of the Bulgarian population by the National Center of Public Health and Analyses ${ }^{9}$ and the National Statistical Institute ${ }^{10}$. Data about the European population were used by European Health for all databases $^{11}$. When we calculated the incidence rates of $\mathrm{CE}$ by age group, we divided the patients into eight groups, as follows: (1-9 years, 10-19 years, $20-29$ years, $30-39$ years, $40-49$ years, $50-59$ years, $60-69$ years, and $70+$ years $^{12}$.

The data were statistically processed with software package SPPS v.24.0. 
Table 1. Distribution of CE patients in Pleven region by demographic characteristics.

\begin{tabular}{|c|c|c|c|}
\hline Variable & N (\%) & Variable & N (\%) \\
\hline $\begin{array}{c}\text { Sex } \\
\text { Males } \\
\text { Females } \\
\text { Total }\end{array}$ & $\begin{array}{c}107(43.1) \\
141(56.9) \\
248(100.0)\end{array}$ & $\begin{array}{c}\text { Age } \\
\text { Average age (yrs) } \\
0-14 \\
15-59 \\
60+ \\
\text { Total }\end{array}$ & $\begin{array}{c}M d n=43.0(4 \div 88) \\
26(10.5) \\
156(62.9) \\
66(26.6) \\
248(100.0)\end{array}$ \\
\hline $\begin{array}{c}\text { Residence } \\
\text { Regional town } \\
\text { Small town (municipality) } \\
\text { Village } \\
\text { Total }\end{array}$ & $\begin{array}{c}51(20.6) \\
70(28.2) \\
127(51.2) \\
248(100.0)\end{array}$ & $\begin{array}{c}\text { Residence (municipality) } \\
\text { Pleven } \\
\text { Cherven bryag } \\
\text { D. Dabnik } \\
\text { Levski } \\
\text { Nikopol } \\
\text { D. Mitropolia } \\
\text { Iskar } \\
\text { Belene } \\
\text { Pordim } \\
\text { Gulyantsi } \\
\text { Knezha } \\
\text { Total }\end{array}$ & $\begin{array}{c}90(36.3) \\
36(14.5) \\
20(8.1) \\
12(4.8) \\
10(4.0) \\
17(6.9) \\
16(6.5) \\
4(1.6) \\
5(2.0) \\
12(4.8) \\
26(10.5) \\
248(100.0)\end{array}$ \\
\hline
\end{tabular}

Table 2. Number of new cases and incidence rates of cystic echinococcosis $(\%)$ in the Pleven region for the two periods compared.

\begin{tabular}{cccccc}
\hline Year & $\begin{array}{c}\text { Number of } \\
\text { cases }\end{array}$ & $\begin{array}{c}\text { Incidence rates } \\
(\%)\end{array}$ & Year & $\begin{array}{c}\text { Number of } \\
\text { cases }\end{array}$ & $\begin{array}{c}\text { Incidence rates } \\
\left(\%{ }_{000}\right)\end{array}$ \\
\hline 1998 & 12 & 3.72 & 2008 & 13 & 4.42 \\
\hline 1999 & 26 & 8.14 & 2009 & 12 & 4.13 \\
\hline 2000 & 24 & 7.62 & 2010 & 4 & 1.50 \\
\hline 2001 & 28 & 8.60 & 2011 & 11 & 4.12 \\
\hline 2002 & 11 & 3.43 & 2012 & 12 & 4.56 \\
\hline 2003 & 14 & 4.43 & 2013 & 5 & 3.93 \\
\hline 2004 & 10 & 3.22 & 2014 & 8 & 2.38 \\
\hline 2005 & 19 & 6.32 & 2015 & 6 & 2.38 \\
\hline 2006 & 8 & 2.65 & 2016 & 6 & 2.42 \\
\hline 2007 & 13 & 4.36 & 2017 & 6 & $3.13^{*}$ \\
\hline Total & 165 & $5.27^{*}$ & Total & 83 & \\
\hline
\end{tabular}

*Mean annual incidence of CE for 1998-2007

The absolute change is calculated from the absolute level $\left(\mathrm{y}_{\mathrm{i}}\right)$ of a single period considered as a base of reference (with fixed base, 1998) or from one period to another (with the base chained) in formulae $\Delta_{\mathrm{i} / 0}=\mathrm{y}_{\mathrm{i}}-\mathrm{y}_{0}$ or $\Delta_{\mathrm{i} / 0}=\mathrm{y}_{\mathrm{i}} \mathrm{y}_{\mathrm{i}-1}$. Also, we calculated dynamic index with fixed base $\left(\mathrm{I}_{\mathrm{i} / 0}\right)$ or with the base chained $\left(\mathrm{I}_{\mathrm{i} / / \mathrm{i}-1}\right)$, respectively using formulae $\mathrm{I}_{\mathrm{i} / 0}=\left(\mathrm{y}_{\mathrm{i}} / \mathrm{y}_{\mathrm{o}}\right) .100$ and $\mathrm{I}_{\mathrm{i} / \mathrm{i}-1}=\left(\mathrm{y}_{\mathrm{i}} / \mathrm{y}_{\mathrm{i}-1}\right) \cdot 100$. Finally, we calculated the rate of increase (decrease), using formula $R_{i / 0}=\left(y_{i}-y_{0} / y_{0}\right) \times 100$ with a fixed base or $R_{i / 0}=\left(y_{i}-y_{i-1} / y_{0}\right) \cdot 100$ with the base chained $^{13,14}$.

CE incidence dynamics was studied using the SPSS Forecasting module. The Spearman correlation was applied, and results were considered significant if $\mathrm{p} \leq 0.05$.

\section{Results}

The study included 248 patients with CE (Table 1). The percentage of women affected was higher than that of men (56.9\% and $43.1 \%$, respectively). The median age was 43.0 years (range $4-88$ years), and a higher proportion (62.9\%) of the patients was in the age group $15-59$ years. Over $51 \%$ were rural residents, and the relative share was the highest of those residing Pleven municipality (14.5\%), Cherven Bryag municipality (14.5\%), and Knezha municipality (10.5\%).

The study covered two periods of the incidence of CE in the Pleven region: 1998-2007 and 2008-2017. The period 2004-2008 was a borderline during which the nation-wide program for echinococcosis control was implemented. 


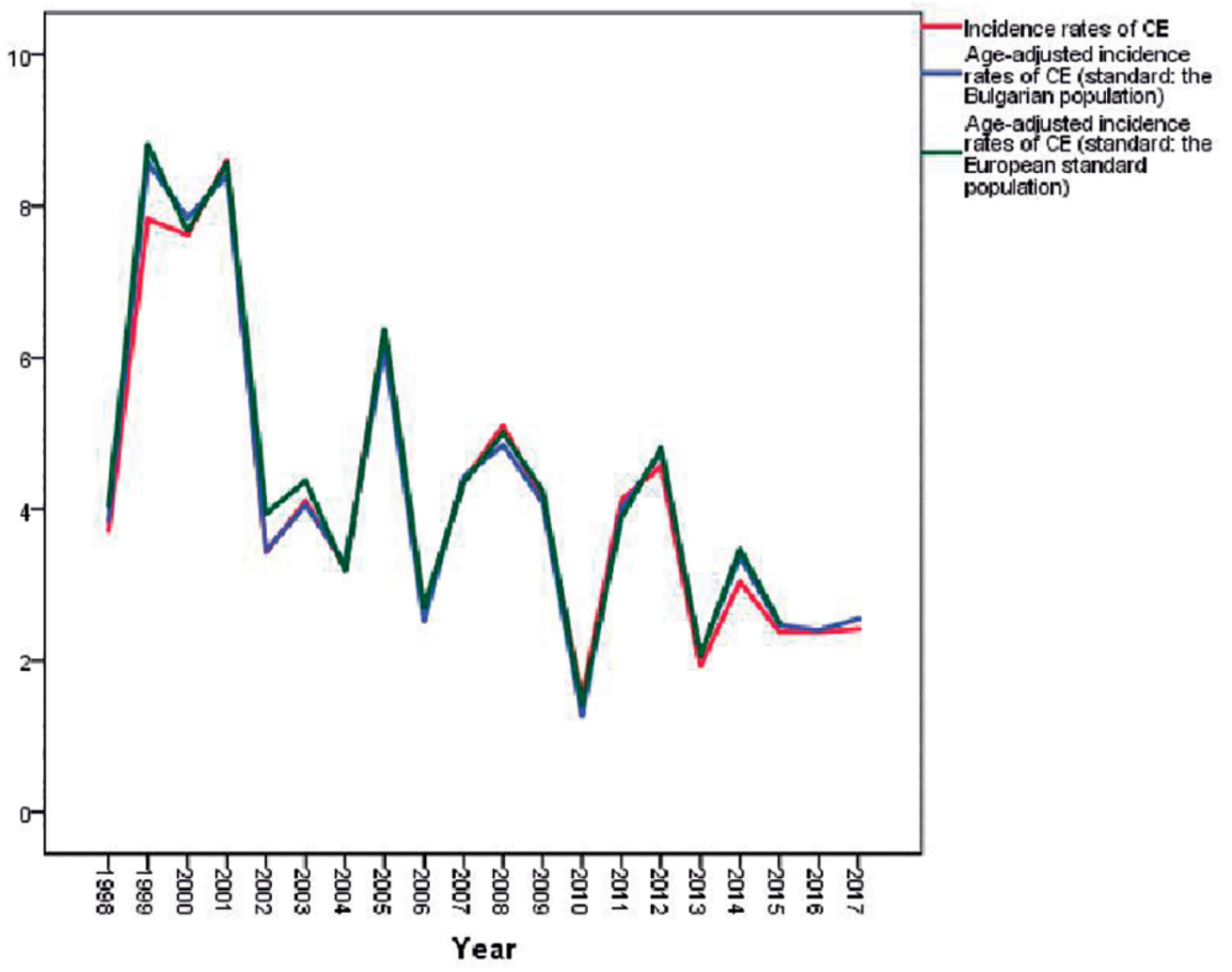

Fig. 1. Dynamics of incidence of $\mathrm{CE}$ and age-adjusted incidence of $\mathrm{CE}$ in the Pleven region for 1998-2017 (per 100000 of the population).

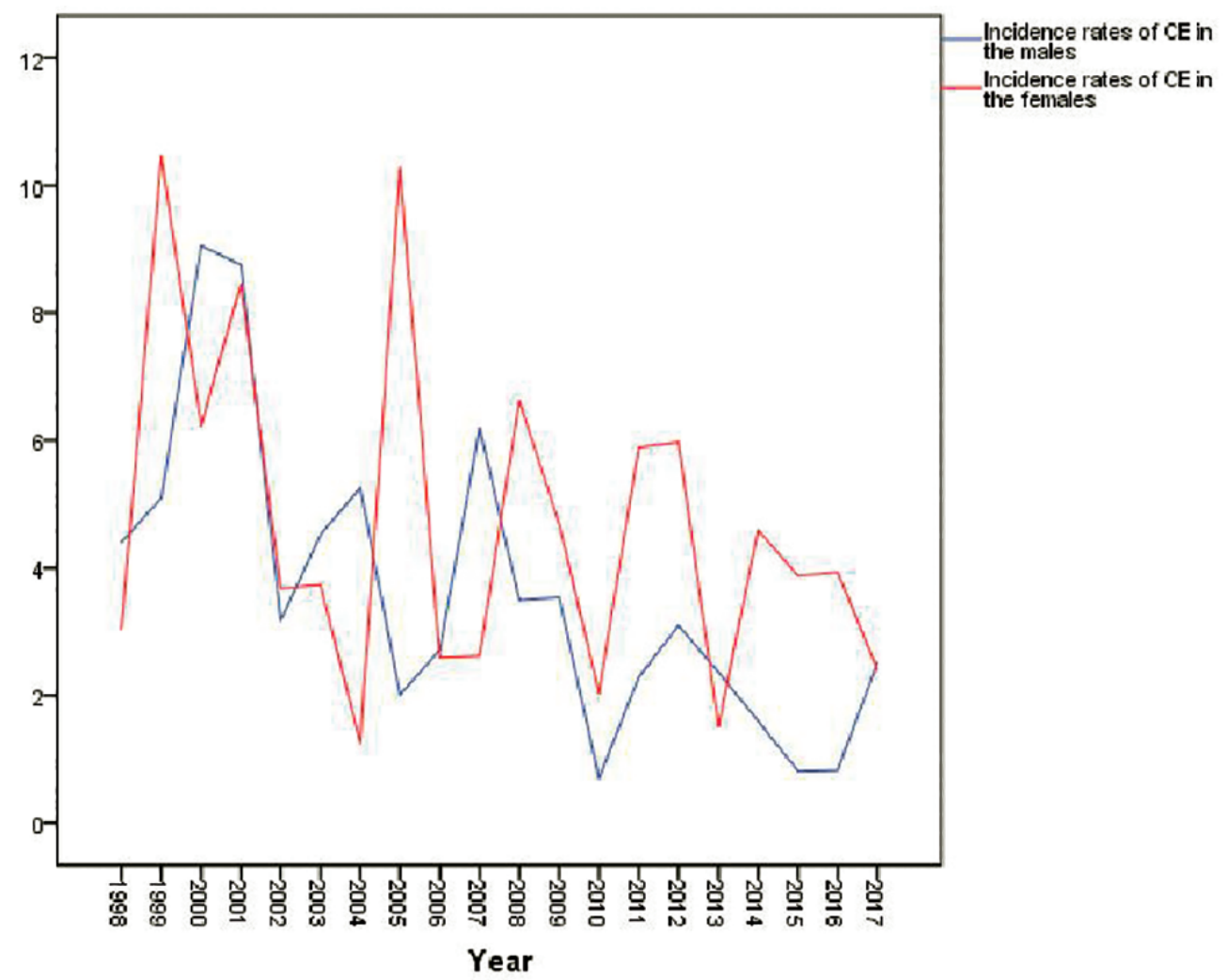

Fig. 2. Dynamics of CE incidence in males and females in the Pleven region for 1998-2017 (per 100000 of the population). 


\section{Incidence rates of $\mathrm{CE}$}

The number of new cases of CE registered per year, and incidence rates of disease are presented in Table 2.

The mean annual incidence rate of $\mathrm{CE}$ in the Pleven region over twenty years was $4.29 \%$. During the first decade (1998-2007), the average annual incidence rate of CE was $5.27 \%$. In 2001, the incidence rate of CE peaked to $8.60 \%$ oooo and was almost equal to the average for the country $(9.21 \%$ о оoо $)$. Such significantly high incidence rates had been registered in the previous years: $1999-8.14 \%, 2000-7.62 \%$ ooo . During the last three years (2015-2017), the incidence rates of $\mathrm{CE}$ in the Pleven region varied between $2.38 \%$ and $2.42 \%$, being lower than the average in the country (between $4.35 \%$ and $3.1 \%{ }^{6}{ }^{6}$.

We also studied the changing dynamics of the CE incidence in the region for the period 1998 -2017 (Table 3). An absolute increase (with fixed base, 1998) was found up to 2001, and then between 2007 and 2009. During the last five years, an absolute decrease has been seen, the values ranging from -0.68 to -1.79 .

Dynamic indexes with fixed base (1998) were highest (values about and over 200\%) during the first three-time intervals (1999, 2000 and 2001), and in 2005 (169.9\%).

The rate of increase (with a fixed base, 1998) was over 100\% in 1999, 2000, and 2001. The rate of increase with the base chained was highest in 1999 (110\% compared to 1998).

Figure 1 presents the dynamics in the incidence rates of $\mathrm{CE}$ and age-adjusted incidence rates of $\mathrm{CE}$ in the Pleven region from 1998 to 2017. We used two populations as a standard: the Bulgarian population and the standard European population.

\section{Incidence rates of CE in males and females}

Figure 2 demonstrates the incidence rates of $\mathrm{CE}$ for both males and females for twenty years. The incidence rates were higher in the females, except for 1998, 2000, 2001, 2003, 2004, 2007, 2013 and 2017. The differences between the incidence rates in males and females were registered for 1998 and 2005. These differences were more distinct between 1998 and 2005. The incidence rates of CE in 1998 in women were twice as high as compared to that in men $(10.47 \%$ and $5.10 \%$, respectively). In 2005 , it was five times higher in women than in men $(10.26 \%$ and $2.01 \%$ ooo , respectively).

Table 3. Dynamics of CE incidence in the Pleven region (1998-2017)

\begin{tabular}{|c|c|c|c|c|c|c|c|}
\hline $\begin{array}{l}\text { Year } \\
x(t)\end{array}$ & $\begin{array}{l}\text { Absolute } \\
\text { levels }\left(\mathrm{y}_{\mathrm{i}}\right)\end{array}$ & $\begin{array}{c}\text { Absolute } \\
\text { change } \Delta_{\mathrm{i} / 0} \\
\text { (with fixed } \\
\text { base, 1998) }\end{array}$ & $\begin{array}{c}\text { Absolute } \\
\text { change } \Delta_{\mathrm{i} / \mathrm{i}-1} \\
\text { (with the base } \\
\text { chained) }\end{array}$ & $\begin{array}{l}\text { Dinamics in- } \\
\text { dex (with fixed } \\
\text { base, 1998) }\end{array}$ & $\begin{array}{l}\text { Dinamics in- } \\
\text { dex (with the } \\
\text { base chained) }\end{array}$ & $\begin{array}{c}\text { Rate of } \\
\text { increase } \\
\text { (decrease) } \\
\mathrm{R}_{\mathrm{i} / 0}(\text { with fixed } \\
\text { base, 1998) }\end{array}$ & $\begin{array}{c}\text { Rate of } \\
\text { increase } \\
\text { (decrease) } \mathrm{R}_{\mathrm{i} / \mathrm{i}-1} \text { e } \\
\text { (with the base } \\
\text { chained) }\end{array}$ \\
\hline 1998 & 3.72 & - & - & 100.0 & 100.0 & - & - \\
\hline 1999 & 7.83 & 4.11 & 4.11 & 210.5 & 210.5 & 110.5 & 110.5 \\
\hline 2000 & 7.62 & 3.90 & -0.21 & 204.8 & 97.3 & 104.8 & 49.8 \\
\hline 2001 & 8.60 & 4.88 & 0.98 & 231.2 & 112.9 & 131.2 & 64.0 \\
\hline 2002 & 3.43 & -0.29 & -5.17 & 92.2 & 39.9 & -7.8 & -3.4 \\
\hline 2003 & 4.11 & 0.39 & 0.68 & 110.5 & 111.8 & 10.5 & 11.4 \\
\hline 2004 & 3.22 & -0.50 & -0.89 & 86.6 & 78.3 & 13.4 & -12.2 \\
\hline 2005 & 6.32 & 2.60 & 3.10 & 169.9 & 196.3 & 69.9 & 80.7 \\
\hline 2006 & 2.65 & -1.07 & -3.67 & 71.2 & 41.9 & -28.8 & -16.9 \\
\hline 2007 & 4.36 & 0.64 & 1.71 & 117.2 & 164.5 & 17.2 & 24.2 \\
\hline 2008 & 5.10 & 1.38 & 0.74 & 137.1 & 116.9 & 37.1 & 31.7 \\
\hline 2009 & 4.13 & 0.41 & -0.97 & 111.0 & 80.9 & 11.0 & 8.0 \\
\hline 2010 & 1.50 & -2.22 & -2.63 & 40.3 & 36.3 & -59.7 & -53.8 \\
\hline 2011 & 4.12 & 0.40 & 2.62 & 110.8 & 274.7 & 10.8 & 26.7 \\
\hline 2012 & 4.56 & 0.84 & 0.44 & 112.6 & 110.7 & 22.6 & 20.4 \\
\hline 2013 & 1.93 & -1.79 & -2.63 & 51.9 & 42.3 & -48.1 & -39.3 \\
\hline 2014 & 3.04 & -0.68 & 1.11 & 81.7 & 157.5 & -18.3 & -35.2 \\
\hline 2015 & 2.38 & -1.34 & -0.66 & 63.9 & 78.3 & -36.0 & -56.3 \\
\hline 2016 & 2.38 & -1.34 & 0.00 & 63.9 & 1.0 & -36.0 & -56.3 \\
\hline 2017 & 2.42 & -1.30 & 0.04 & 65.1 & 101.7 & .34 .9 & -54.6 \\
\hline
\end{tabular}


Table 4. Dynamics of CE incidence by age groups in the Pleven region for 1998-2017 (per 100000 of the population)

\begin{tabular}{ccccccccc}
\hline \multirow{2}{*}{ Year } & \multicolumn{7}{c}{ Age groups } \\
\cline { 2 - 9 } & $1-9$ & $10-19$ & $20-29$ & $30-39$ & $40-49$ & $50-59$ & $60-69$ & $70+$ \\
\hline 1998 & 9.69 & 0.00 & 2.49 & 0.00 & 4.40 & 9.37 & 4.90 & 0.00 \\
\hline 1999 & 6.71 & 4.95 & 2.51 & 12.50 & 6.74 & 11.47 & 17.58 & 0.00 \\
\hline 2000 & 6.98 & 7.58 & 7.63 & 7.62 & 9.28 & 13.43 & 0.00 & 7.18 \\
\hline 2001 & 7.14 & 4.95 & 22.65 & 9.63 & 2.25 & 8.50 & 4.99 & 6.77 \\
\hline 2002 & 0.00 & 0.00 & 0.00 & 4.86 & 4.56 & 8.51 & 2.57 & 4.49 \\
\hline 2003 & 0.00 & 10.36 & 0.00 & 2.44 & 2.32 & 4.26 & 5.29 & 6.70 \\
\hline 2004 & 3.91 & 2.68 & 2.68 & 9.80 & 2.35 & 0.00 & 0.00 & 4.42 \\
\hline 2005 & 0.00 & 8.41 & 2.94 & 4.92 & 2.41 & 10.90 & 16.17 & 2.23 \\
\hline 2006 & 3.97 & 5.83 & 0.00 & 0.00 & 0.00 & 2.22 & 8.06 & 2.24 \\
\hline 2007 & 0.00 & 3.08 & 5.94 & 7.44 & 10.02 & 0.00 & 5.28 & 2.27 \\
\hline 2008 & 0.00 & 6.50 & 2.97 & 2.55 & 5.03 & 4.14 & 12.94 & 6.90 \\
\hline 2009 & 3.93 & 0.00 & 8.96 & 5.17 & 2.52 & 2.37 & 7.62 & 2.32 \\
\hline 2010 & 0.00 & 3.57 & 0.00 & 0.00 & 0.00 & 2.45 & 2.48 & 2.36 \\
\hline 2011 & 0.00 & 4.04 & 3.59 & 8.99 & 2.82 & 0.00 & 4.84 & 7.15 \\
\hline 2012 & 0.00 & 8.36 & 14.54 & 3.10 & 2.84 & 5.24 & 2.43 & 2.40 \\
\hline 2013 & 0.00 & 0.00 & 3.74 & 9.57 & 0.00 & 2.68 & 0.00 & 0.00 \\
\hline 2014 & 4.40 & 8.71 & 0.00 & 6.61 & 5.71 & 2.73 & 0.00 & 0.00 \\
\hline 2015 & 0.00 & 8.87 & 0.00 & 3.40 & 5.73 & 0.00 & 0.00 & 2.43 \\
\hline 2016 & 0.00 & 0.00 & 0.00 & 10.46 & 0.00 & 2.90 & 2.57 & 2.34 \\
\hline 2017 & 0.00 & 8.93 & 0.00 & 0.00 & 2.90 & 5.96 & 2.65 & 0.00 \\
\hline
\end{tabular}

Incidence rates of $\mathrm{CE}$ registered in age groups

We studied the changes in the levels of CE incidence in the age groups (Table 4).

The data in Table 4 show that during the period 1998-2003, before the implementation of the national program for echinococcosis control in animals and humans, the age groups most affected were those of 1-9 years and 50-59 years (values approximately $10 \%$ ).

After 2004 the incidence rates of CE dropped in the youngest age group (1-9 years), while in the $50+$ age groups, there were markedly unstable dynamics. Only after 2012, the decrease in the incidence rate of CE was more stable.

\section{Incidence rates of cystic echinococcosis ac- cording to the place of residence}

Of the 248 patients with CE, 127 (51.2\%) lived in rural areas.

Figure 3 shows that the incidence rates of $\mathrm{CE}$ were higher in the rural population in the Pleven region throughout the period studied, except for 2003, 2005, 2012 and 2013. The most striking differences were between incidence rates registered in 2000 and 2001, when the incidence rates for the rural population were about three times as high as that in the urban population, respectively $13.62 \%$ and $4.05 \%$ (2000), and $15.61 \%$ aooo, and $4.76 \%{ }_{\text {oooo }}(2001)$. Table
1 and Figure 4 present the proportions of patients with $\mathrm{CE}$ in the municipalities of the Pleven region. The highest proportion of CE cases was that for the Pleven municipality - 36.3\%. Pleven municipality is the municipality with the highest number of settlements in the Pleven region, which explains why the highest proportion of CE cases was found there. Higher proportions were also found in small municipality towns: Cherven Bryag - 14.5\%, Knezha 10.5\%, D. Dabnik - 8.1\%, D. Mitropolia - 6.9\%.

\section{Discussion}

CE is an important public health problem because of its wide distribution, the long asymptomatic course of the disease and the possible complications. $\mathrm{CE}$ is found in the following regions: Asia, Australia, Africa, parts of South America and Southeastern Europe $^{15}$. In 2017, CE was reported in 24 states in the EU/EEA, in which a total of 832 confirmed cases were reported $(0.18 \%)$. Bulgaria had the highest number of cases $-26 \%$ of reported cases in the EU/ EEA region (an incidence rate of $3.07 \%$ ), followed by Germany (15\%), Spain (10\%) and Poland (9\%) ${ }^{16}$. A relatively high prevalence rate for $\mathrm{CE}$ was reported in other countries in the Balkan region. In an 


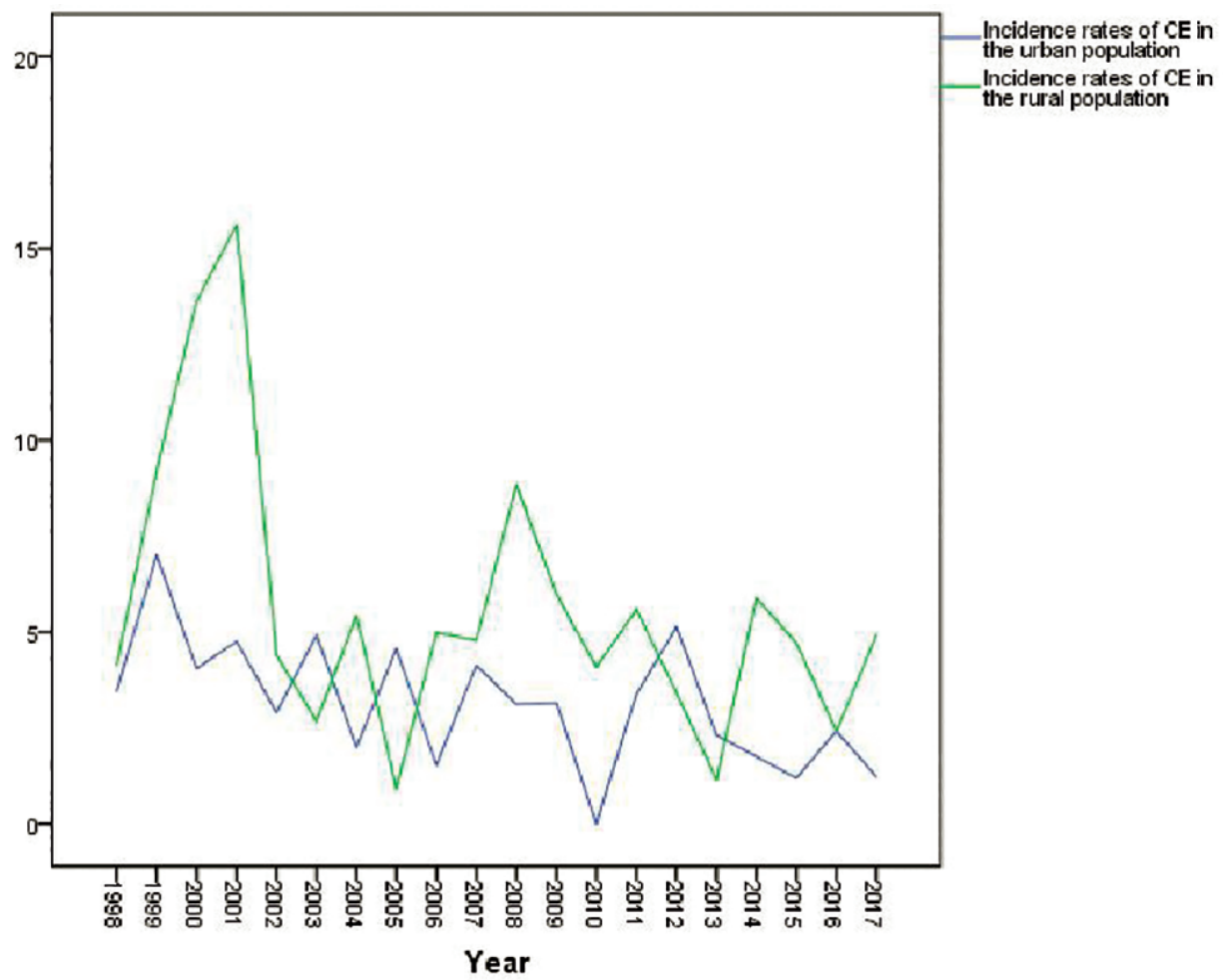

Fig. 3. Dynamics of CE incidence by place of residence in the Pleven region for 1998-2017 (per 100000 of the population).

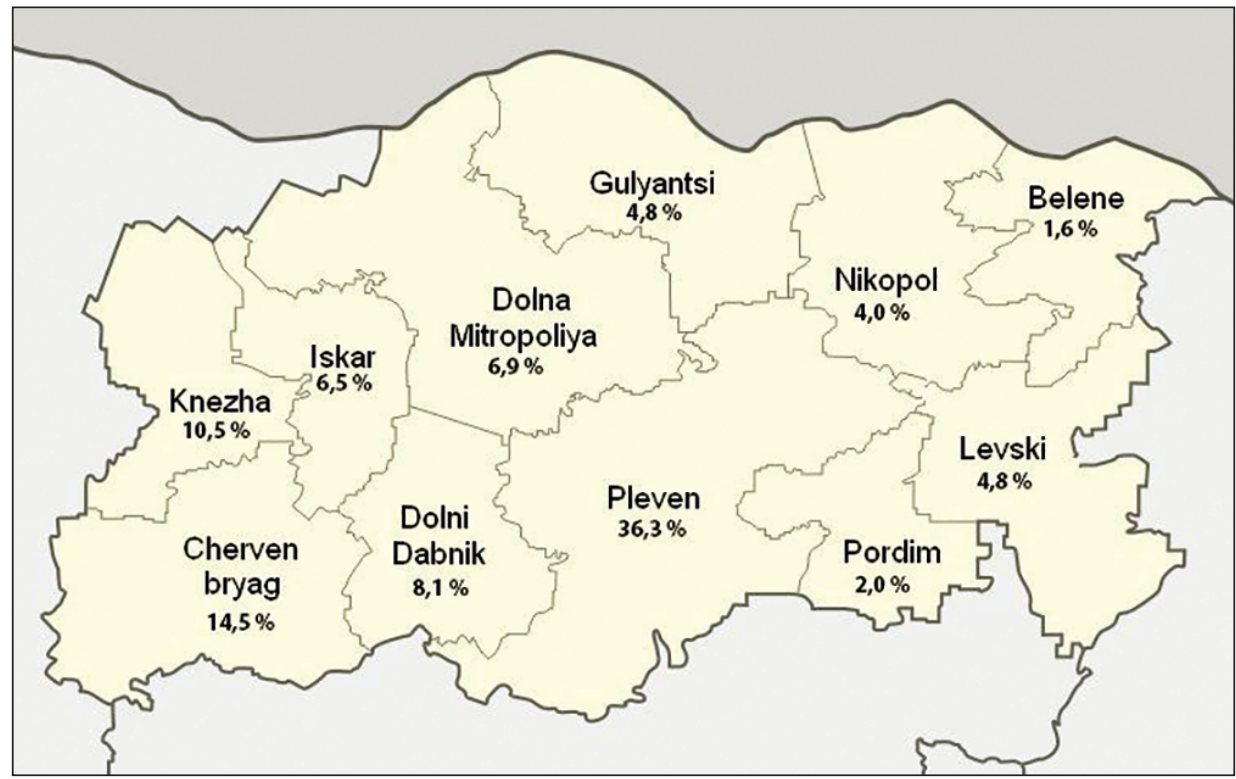

Fig. 4. Structure of the patients with CE in the Pleven region municipalities for 1998-2017

ultrasound cross-sectional survey, rural inhabitants of Bulgaria, Romania and Turkey were screened for abdominal CE, which showed an age and sex adjusted prevalence of $0.41 \%$ for Bulgaria and Romania and of $0.59 \%$ for Turkey ${ }^{17}$. In 2015, in Serbia an echinococcosis incidence rate of $0.73 \%$ was reported ${ }^{18}$.
The incidence rates for CE vary significantly in the different regions of Bulgaria. The regions with the highest incidence are the Burgas, Sliven and Plovdiv regions. The Pleven region occupies a territory of $4653 \mathrm{~km}^{2}$, and the population is 269,759 , distributed in 11 municipalities. Epidemiological studies on the geographic distribution of $\mathrm{CE}$ in the Pleven region 
are not new. As early as the period $1950-1962$ in the Pleven region, a high CE incidence was reported $(9.5 \%)$, which was higher than the country's average at the time $\left(6.5 \%{ }^{19}\right.$. Another study by Lalova et al. for the period $1950-1972$ also showed a high incidence of $\mathrm{CE}$ in the Pleven region ${ }^{20}$. Similar results by Boshnakova et al. were reported for the period $1985-1998^{21}$. In Bulgaria, the first reported family outbreaks of CE were in the Pleven region ${ }^{22}$. The CE incidence in the Pleven region has risen and fallen during the last decades. It was generally similar to the overall prevalence in Bulgaria. We found significant differences in the incidence rates between the two periods. The first period had an incidence of $5.27 \%$ 。oo During the second period (after the implementation of the nation-wide program for echinococcosis control), a tendency for a decrease and stabilizing of the incidence of CE was established: the mean annual incidence rate during this period was of $3.13 \%$

Although we expected that the incidence rates of $\mathrm{CE}$ in the Pleven region would be higher (compared to the age-adjusted incidence rates of CE for the Bulgarian and European standard population), given the aging of the population in the region, the three curves overlap (Fig. 1) almost completely, demonstrating similar changes in dynamics.

Comparing the actual incidence rate for $\mathrm{CE}$ in the Pleven region with the age-adjusted incidence rates of CE for the Bulgarian and European standard population, it does not show any statistical differences. The only exceptions were those for the time intervals in the dynamics in 1999, 2014, and 2015, when the incidence rates of $\mathrm{CE}$ were lower than those for age-adjusted incidence rates of CE, and in 2008, when the opposite trend was registered.

We examined a Spearman rank correlation between the incidence rates of CE and the implementation of the national program for control of echinococcosis in humans and animals. The results showed a moderate negative correlation, i.e., the implementation of the program resulted in lowering the levels of $\mathrm{CE}$ incidence rates $(\mathrm{r}=-0.454 ; \mathrm{p}=0.044 ; \mathrm{N}=20)$. The measures taken during the implementation of the nation-wide program for echinococcosis control resulted in a decrease in the incidence rates for $\mathrm{CE}$ in the Pleven region.

We analyzed the incidence rates of CE by sex, age, and place of residence (Table 1).

Our study (Table 1) confirmed the findings reported by other authors that women are more often affected $^{2,23}$. They are more often engaged in looking after pets and gardening, and such activities imply exposure to the infection.

Despite that in the last decade, there has been a trend towards a lowering of the $\mathrm{CE}$ incidence rates among young patients, the existence of relatively high incidence rates in the young age group and the active population, suggest that there is ongoing transmission of the disease. The latter finding implies the necessity of continuing the active measures to control the source of infection.

In our study, we show that the $\mathrm{CE}$ incidence rate is higher among the population living in the rural parts of the Pleven region. The differences in incidence between rural and urban populations were very pronounced during the 2000-2001 period. Despite urbanization and the demographic changes in Bulgaria during the last decades, the rural population retains a higher incidence rate. From the 248 patients with primary CE in our study, 127 (51.2\%) live in rural areas. The urban population of the Pleven region is around twice the size of the rural population (urban - 161 005, rural - 79375); however, half of the reported CE cases are rural ${ }^{24}$. These figures warrant the assumption that social factors and living conditions in villages are predisposing to the infection with Echinococcus granulosus. Our results confirm the results stated in the National Program for Echinococcosis Control and the conclusions made in Muhtarov's dissertation in the south-eastern Rhodope region ${ }^{23}$. Because of the high incidence rates of $\mathrm{CE}$ in the region, building a regional program for echinococcosis control was initiated, joining the efforts of veterinary medical services, the regional and local authorities, general practitioners, and other medical professionals. Several guidelines were provided for lowering the incidence of the disease in the region. The guidelines included raising the level of awareness of the population on the disease, mass immune screening in the places with high incidence, ongoing monitoring (analysis and assessment) of CE incidence in the region, sanitation measures including stricter control on meat processing establishments, and setting up kennels for stray dogs and places for walking pet dogs. These measures overlapped with the ones recommended in the national program, introduced in 2004, and contributed to the gradual decrease of the incidence.

\section{Conclusions}

The study on the CE incidence in the Pleven region suggests the following conclusions:

The mean annual incidence rate of CE in the Pleven region for the 20-year-period was $4.29 \%$ ooo After the implementation of the national program for echinococcosis control, the mean annual incidence rate dropped from $5.27 \%$ (the period before implementation) to $3.13 \%$ (the period after implementation). There is a moderate negative correlation between 
the $\mathrm{CE}$ incidence rate and the implementation of the national program for echinococcosis in humans and animals $(\mathrm{r}=-0.454 ; \mathrm{p}=0.044 ; \mathrm{N}=20)$. No differences were found between the incidence rates of $\mathrm{CE}$ and age-adjusted incidence rates of $\mathrm{CE}$ in the region.

Analyses of data on patients operated on for CE showed that women $(56.9 \%)$ were more often affected than men, the incidence rates were higher in the rural population $(51.2 \%)$, and in the people of active age $(62.9 \%)$.

\section{Author contributions:}

Conceptualization, I.A.A. and Z.S.B.; methodology I.A.A. and J.I.S.; software, J.I.S.; validation I.A.A. and L.S.S.; formal analysis, I.A.A. and J.I.S.; investigation, M.P.L. and L.S.S.; resources, I.A.A., Z.S.B., and L.S.S.; data curation, I.A.A., Z.S.B., L.S.S., and M.P.L.; writing - original draft preparation, I.A.A.; writing - review and editing, M.P.L., J.I.S., and L.S.S.; visualization, I.A.A. and L.S.S.; supervision, I.A.A.; project administration, J.I.S. All the authors have read and agreed with the final version of the article.

\section{Compliance with Ethics Requirements:}

"The authors declare no con. flict of interest regarding this manuscript." "This study received no specific grant from any public, commercial or non-profit funding agency." "Public available databases were used in accordance with the Bulgarian law for Access to Public Information. Data was collected from epidemiological studies of the Regional Health Inspectorate - Pleven, Bulgaria with their permission."

\section{Acknowledgments: none}

\section{References}

1. Boeva V. Echinococcosis, in Clinical parasitology and Tropical Medicine Petrov P, Kurdova R. (eds). Sofia, East-West, 2016:323-340.

2. Todorov T, Boeva V. Human echinococcosis in Bulgaria: a comparative epidemiological analysis. Bull World Health Organ. 1999;77:110-118.

3. The European Union summary report on trends and sources of zoonoses, zoonotic agents and food-borne outbreaks in 2017. Available at: https://www.ecdc.europa. $\mathrm{eu} / \mathrm{en} /$ publications-data/european-union-summary-report-trends-and-sources-zoonoses-zoonotic-agents-and-10. (Accessed on November 19, 2019).

4. Todorov T, Boeva V. Echinococcosis in children and adolescents in Bulgaria: a comparative study. Ann Trop Med Parasitol. 2000;94:135-144.

5. Jordanova D, Harizanov R, Kaftandjiev I, Rainova I, Kantardjiev T. Cystic echinococcosis in Bulgaria 1996-2013, with emphasis on childhood infections. Eur J Clin Microbiol Infect Dis. 2015;34:1423-1428.

6. Rainova I, Harizanov R, Tzvetkova N, et al. Analysis of parasitic diseases in Bulgaria in 2017. The XVI ${ }^{\text {th }}$ National Congress of Clinical Microbiology and Infections of BAM, May 10-12, 2018, Sofia, Bulgaria.

7. Bulgarian national program for control of cystic echinococcosis in humans and animals 2004-2008. Available at http://webcache.googleusercontent.com/search?q=cache:3-k Zic1yOlYJ:strategy.bg/FileHandler.ashx\%3FfileId\%3D553+ $\& c d=1 \& h l=b g \& c t=c \ln k \& g l=b g($ Accessed on November 19, 2019).

8. Demographic and health survey data of the population of the Pleven region. Regional Health Inspectorate - Pleven. Available at https://rzi-pleven.com/category/демография/ (Accessed on November 15, 2018).

9. Healthcare Archives. The National Center of Public Health and Analyses (NCPHA). Available at http://ncphp.government.bg/index.php?option $=$ com_content $\&$ view $=$ category $\mathcal{Q}$ $\mathrm{id}=166 \&$ Itemid $=50 \&$ lang $=$ bg (Accessed on November 15 , 2018).

10. Population (Demography, Migration and Projections). National Statistical Institute. Available at http://www. nsi.bg/en/content/6593/population-demography-migration-and-projections (Accessed on November 15, 2018).

11. European Health for All databases. WHO. Regional Office for Europe. Available at: https://gateway.euro.who.int/en/ datasets/european-health-for-all-database/ (Accessed on November 15, 2018).

12. Grancharova G, Velkova A, Alexandrova S. Demographic approaches to the study and evaluation of public health, in Social medicine, $2^{\text {nd }}$ ed, Grancharova G (ed). Pleven, Medical University - Pleven, 2006:124-136.

13. Grancharova G, Hristova P. Medical Statistics, $1^{\text {st }}$ edn. Pleven, Medical University - Pleven, 2004.

14. Hristova P. Methodology of scientific research and biostatistics in medicine and healthcare. Pleven, Medical University - Pleven, 2014.

15. Grosso G, Gruttadauria S, Biondi A, Marventano S, Mistretta A. Worldwide epidemiology of liver hydatidosis including the Mediterranean area. Gastroenterol. 2012;18(13): 1425-1437.

16. European Centre for Disease Prevention and Control. Echinococcosis - Annual Epidemiological Report for 2017. Available at https://www.ecdc.europa.eu/en/publications-data/echinococcosis-annual-epidemiological-report-2017 (Accessed on December 10, 2019).

17. Tamarozzi F, Akhan O, Cretu CM, et al. Prevalence of abdominal cystic echinococcosis in rural Bulgaria, Romania, and Turkey: a cross-sectional, ultrasound-based, population study from the HERACLES project. Lancet Infect Dis. 2018;18(7):769-778.

18. Colovic Calovski I, Barac A, Golubovic Z, et al. Case-series study of hepatic echinococcal cysts in Serbia: viability of scolices, seropositivity and epidemiological characteristics. J Helminthol. 2018;92(2):161-167.

19. Todorov T, Nenov S, Genov G, et al. Study on echinococcosis in Bulgaria. Modern Medicine. 1967;18(12):1024-1033.

20. Lalova I, Boeva V, Petrov P, Marinova V. Study on epidemiology of human echinococcosis in the Pleven region. Problems of Infectious and Parasitic Diseases. 1974;2: 209-215.

21. Boshnakova G, Angelov I, Pomakova D, Ilieva A. Incidence of echinococcosis in the Pleven region between 1985-1998. Infectology. 2001;37(1):26-27. 
22. Angelov I, Vouchev D. Familial foci of echinococcosis. Infectology. 2010;47(1): 44-45.

23. Muhtarov M. Study of cystic echinococcosis in the south-eastern Rhodopes region of Bulgaria (Kurdjali, Smolyan and Haskovo regions). Dissertation 2016, National Center for Infectious and Parasitic Diseases.
24. Population by districts, municipalities, place of residence and sex. National Statistical Institute. Available at https:// www.nsi.bg/en/content/6704/population-districts-municipalities-place-residence-and-sex. (Accessed on November 19, 2019). 